\title{
Air Entrapment Issues in Piping for a Small Hydroelectric Station in Western North Carolina
}

\section{Dr. George D. Ford, Western Carolina University}

Dr. George Ford P.E. is an associate professor in the Construction Management Department at Western Carolina University.

\section{Dr. Hayrettin B. Karayaka, Western Carolina University}

Bora Karayaka is an Engineering faculty at Kimmel School, Western Carolina University. He has worked as a Senior Engineer for smart grid and wireless communication industries for over ten years. He is currently responsible for teaching electric power engineering courses in the department.

Dr. Karayaka's research interests include power engineering education, ocean wave energy harvesting, identification, modeling and control for electrical machines and smart grid. He received his B.S. and M.S. degrees from Istanbul Technical University in Control and Computer Engineering and his $\mathrm{PhD}$ degree in Electrical Engineering from The Ohio State University.

\section{Dr. Sung Joon Suk, Western Carolina University}




\title{
Air entrapment issues in piping for a small hydroelectric station in western North Carolina
}

\begin{abstract}
A team from Western Carolina University's Rapid Center in Cullowhee, North Carolina visited a local fish farm to determine why a previously installed stream-powered, electricity generating system was not working correctly. The team met the owner and a local Agricultural Extension Office Manager (AEOM), at the site. The AEOM provided the team with a tour of the primary structures and equipment.
\end{abstract}

The system inspected consists of four water-powered impulse type turbines connected to 1320 feet of 8-inch black plastic, seamless pipe. The pipe inlet provides 98 feet of head (42.2 psig) to power the turbines. The turbines provide wattage generation based upon delivered water flow at a specific pressure. The higher the water flow and pressure, the higher the turbine wattage output, up to 1 kilowatt each, maximum output as installed. The turbines appeared to operate correctly, but the water pressure was measured to be less than optimum, affecting the turbine wattage output.

The team inspected the length of the pipeline and found issues of concern. First, the pipe inlet suction structure was not totally flooded. It appeared that air might be introduced into the pipeline through the suction opening by the venturi effect. Secondly, the static pressure readings taken at the turbine building were not as expected. The expected static pressure, considering the 98 feet of head was $42.4 \mathrm{psig}$. The actual reading was $22 \mathrm{psig}$. The team discussed the static pressure issue and inspected the pipeline, finding two sections were not flooded with water and contained air. There were sections of the pipeline, which had slipped off their support structures.

Since no major leaks were detected, air entrapment was considered as the cause of the head pressure issues. The sections of the pipeline which were out of position and had slipped off their support structures could trap air. This paper discusses the measures taken to correct the inlet water piping to the stream powered turbines. 


\section{Introduction}

A team of engineers and graduate students from Western Carolina University's Rapid Center visited a trout fish farm near Robbinsville, North Carolina to determine why a previously installed stream powered, electricity generating system was not working correctly. The Team met the owner and a local Agricultural Extension Office Manager (AEOM), at the site. The AEOM provided the team with the history of the system and a tour of the primary structures and equipment which had been installed by a professional solar, hydroelectric power installation contractor.

The Rapid Center is a university-based research and development center. The Center's industryexperienced faculty and staff work with business partners to address their specific needs and to remove obstacles to product commercialization and process improvement. The Rapid Center fosters a culture of collaborative innovation that helps clients refine existing products, develop new ones and improve business practices. At the same time, the Center's engineering and technology students, working with faculty mentors and course instructors, work to address realworld problems for project sponsors while they gain hands-on experience during the twosemester senior capstone project. [1]

\section{Discussion}

The turbine system inspected consists of four water-powered, impulse type turbines connected to about 1320 feet of 8 -inch seamless black plastic pipe. The pipe inlet provides 98 feet of head (42.2 psig) to power the turbines. The turbines provide a certain wattage generation based upon delivered water flow at a specific pressure, see Table 1. The higher the water flow and pressure, the higher the turbine wattage output. The turbines appear to operate correctly, but the supply water pressure was measured to be less than optimum, affecting the turbine wattage output. Maximum output for each turbine is 1900 watts each, but for the system as installed, 1000 watts each is expected. For this system, 8" pipe will convey 700 gpm per Crane No. 410 [3] with less than 2 psig pressure drop in 1300 feet. At 98 feet of head, each turbine can produce 1000 watts $(1 \mathrm{KW})$ of power at 12 volts, direct current. The required flow rate for the four turbines combined is 448 gpm total, well within the capabilities of the plastic supply line. 


\section{Stream Engine Output in Watts (Continuous)}

\section{Flow rate:}

Liters per second (LPS)

Gallons per minute (GPM)

\begin{tabular}{ll|c|c|c|c|c|c|c|} 
& \multicolumn{2}{c}{$\mathbf{0 . 6 7}$} & $\mathbf{1 . 3 3}$ & $\mathbf{2 . 5}$ & $\mathbf{5}$ & $\mathbf{6 . 6 7}$ & $\mathbf{7 . 5}$ & $\mathbf{9 . 5}$ \\
Meters & $\mathbf{F t}$ & $\mathbf{1 0}$ & $\mathbf{2 0}$ & $\mathbf{4 0}$ & $\mathbf{7 5}$ & $\mathbf{1 0 0}$ & $\mathbf{1 1 2}$ & $\mathbf{1 5 0}$ \\
\cline { 3 - 9 } $\mathbf{3}$ & $\mathbf{1 0}$ & $* *$ & 20 & 40 & 75 & 100 & 130 & 150 \\
\cline { 3 - 9 } $\mathbf{6}$ & $\mathbf{2 0}$ & 15 & 40 & 80 & 150 & 200 & 250 & 350 \\
\cline { 3 - 9 } $\mathbf{1 5}$ & $\mathbf{4 9}$ & 45 & 100 & 200 & 375 & 500 & 650 & 800 \\
$\mathbf{3 0}$ & $\mathbf{9 8}$ & 80 & 200 & 400 & 750 & 1000 & $* *$ & $* *$ \\
$\mathbf{6 0}$ & $\mathbf{1 9 7}$ & 150 & 400 & 800 & 1500 & $* *$ & $* *$ & $* *$ \\
$\mathbf{9 0}$ & $\mathbf{2 9 5}$ & 200 & 550 & 1200 & $* *$ & $* *$ & $* *$ & $* *$ \\
$\mathbf{1 2 0}$ & $\mathbf{3 9 4}$ & 300 & 700 & 1500 & $* *$ & $* *$ & $* *$ & $* *$ \\
\hline $\mathbf{1 5 0}$ & $\mathbf{4 9 2}$ & 400 & 850 & 1900 & $* *$ & $* *$ & $* *$ & $* *$ \\
\hline
\end{tabular}

Table 1: Source: Energy Systems and Design Ltd. PO Box 4557 Sussex NB Canada E4E 5L7

The team inspected the length of the pipeline and found several issues of concern. First, the pipe inlet suction structure was not totally flooded. It appeared that air could be introduced into the pipeline through the suction opening. Figure 1, below, shows the inlet structure. It is an open concrete tank holding live trout in one end and housing the suction line (shown in Figure 2) at the other end.

The water level above the suction line did not appear to be sufficient. A fitting was installed to the overflow pipe to increase the water level in the tank and appeared to reduce or eliminate the eddies observed at the pipeline inlet. The inlet screens were fouled significantly and were cleaned further improving the suction line condition. There was also a "bypass" piping 


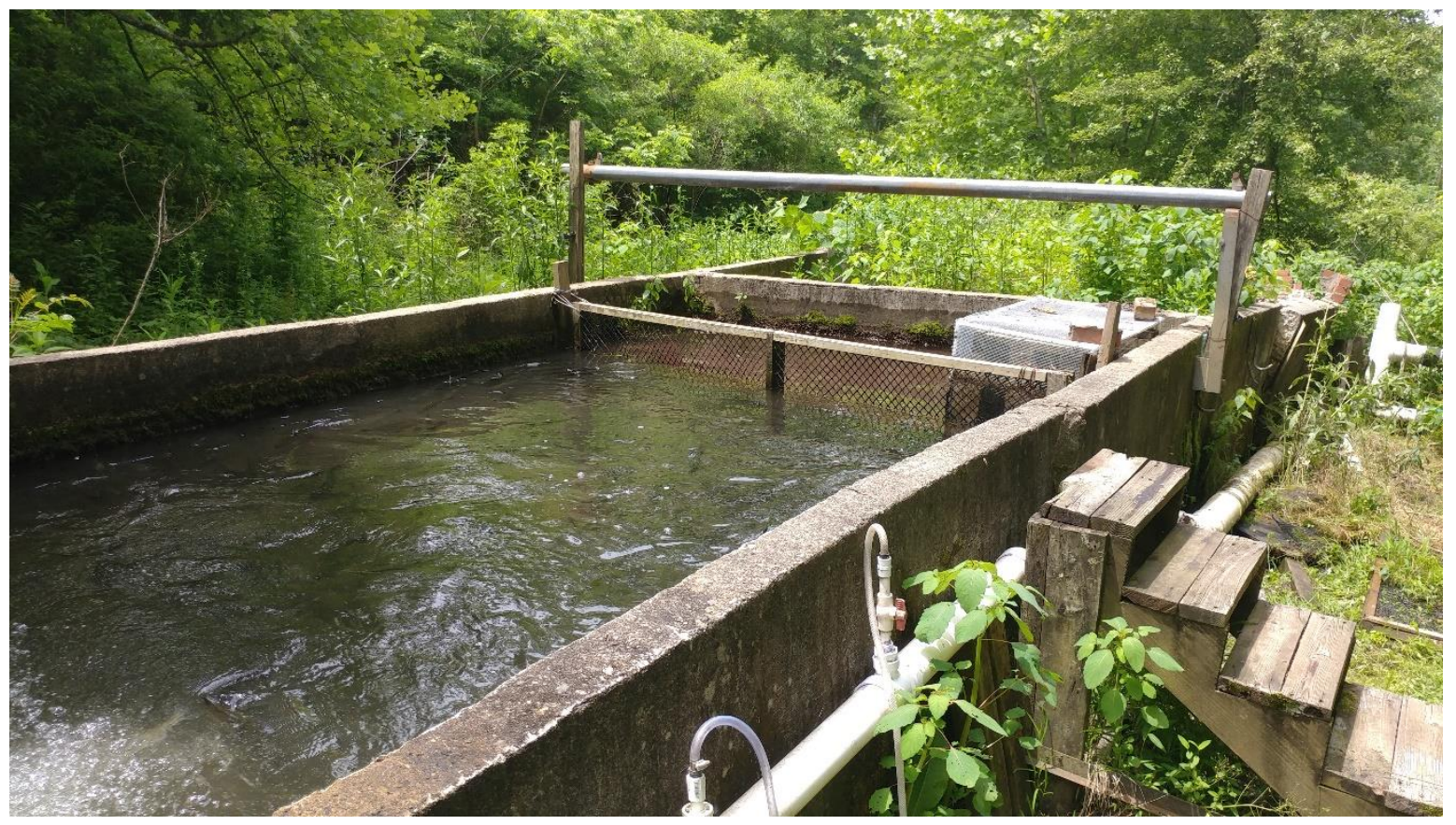

Figure 1

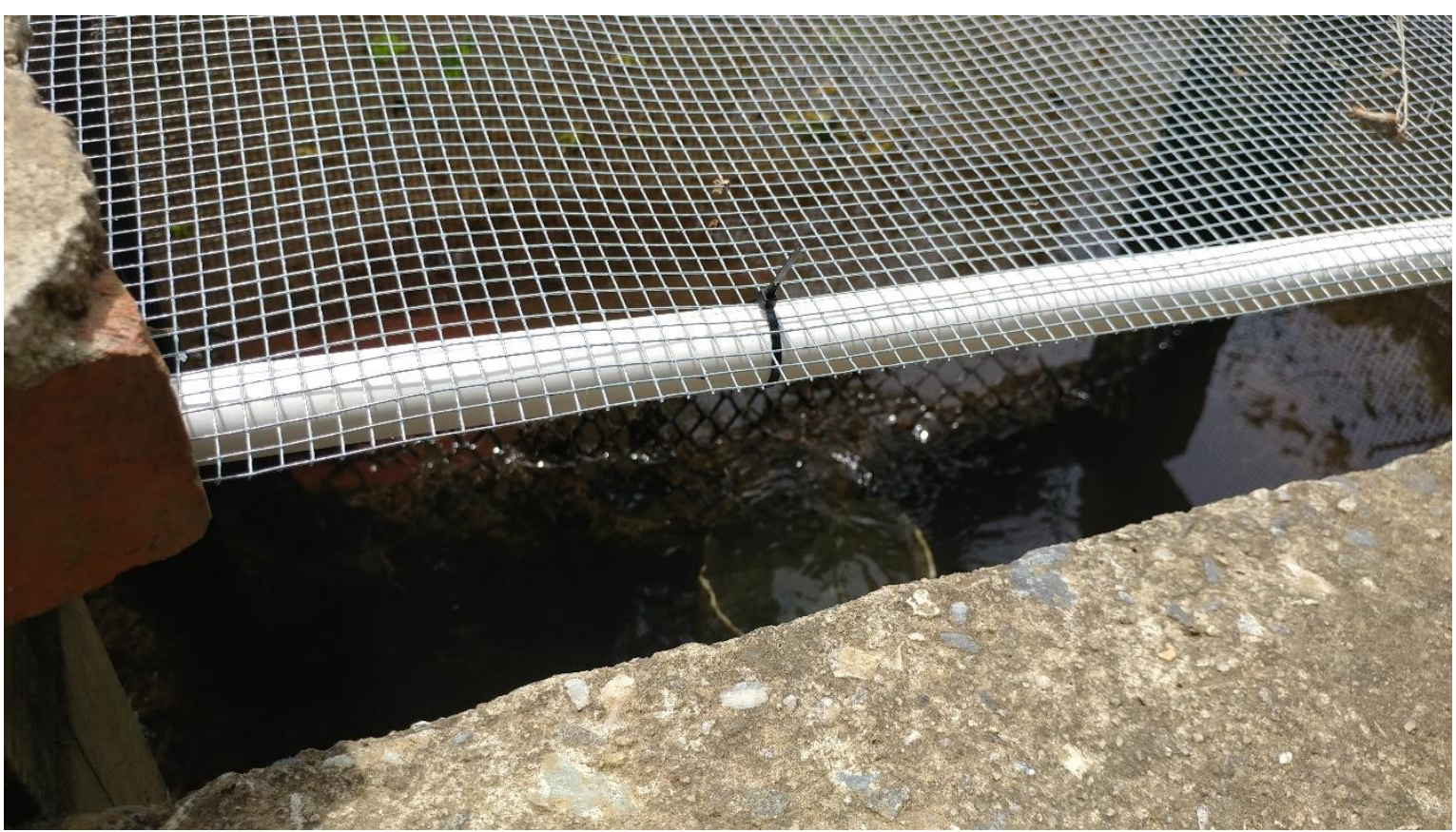

Figure 2

arrangement connecting the system pipeline which could potentially allow air infiltration to the system pipeline, see Figure 3. Fittings and tools were not available to modify this bypass piping. 


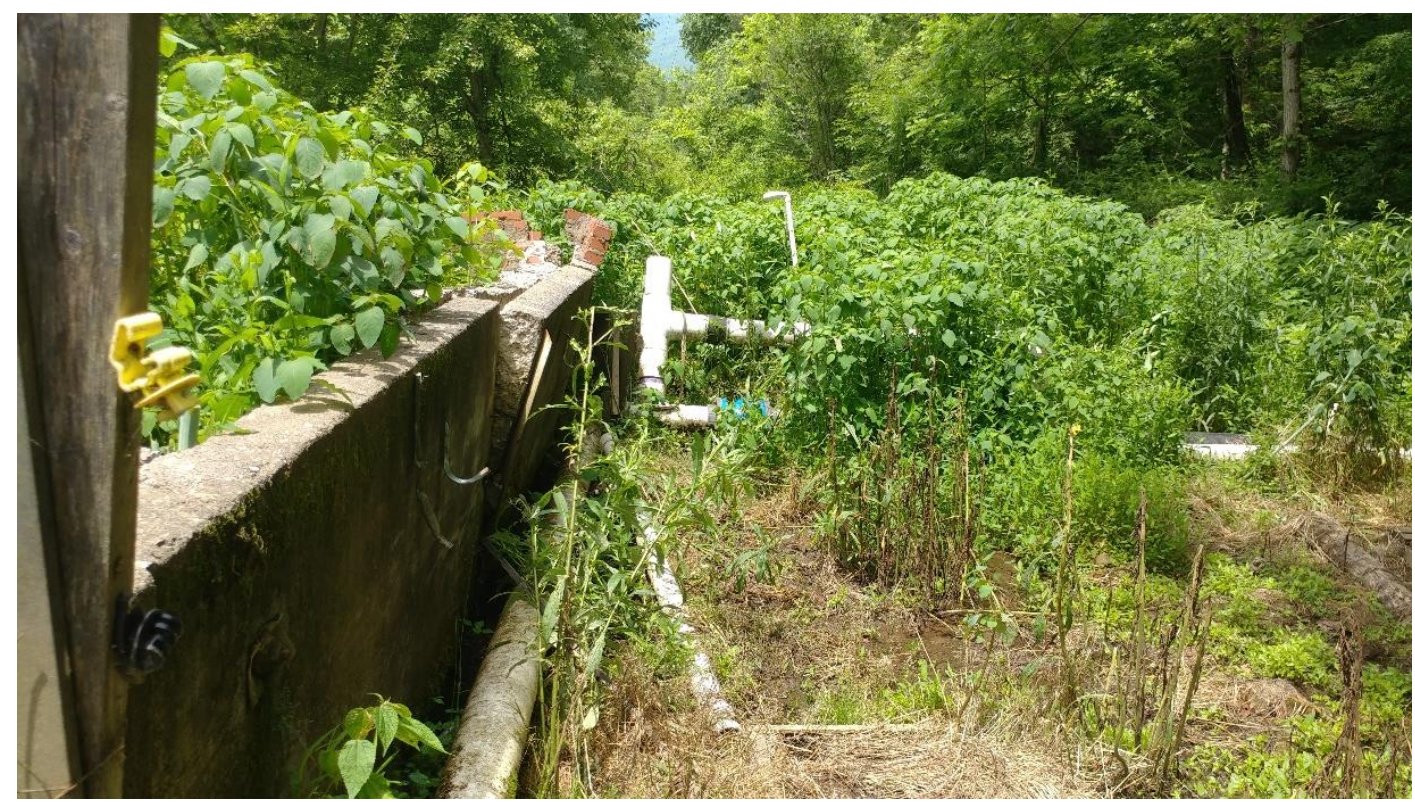

Figure 3

The system pipeline was flooded, and static pressure readings were taken at the turbine building. The expected static pressure, considering the 98 feet of head was $42.2 \mathrm{psig}$. The actual reading was 22 psig. The team discussed the static pressure issue and inspected the pipeline, finding two sections were not flooded with water, even after waiting a period for the pipeline to fill under a no turbine flow condition. There were no significant leaks, but there were sections of pipe which had slipped off their supports allowing significant elevation changes in the supply piping.

Since no major leaks were detected, air entrapment was considered the culprit of the low supply pressure. The sections of the pipeline which were out of position could trap air on the downhill side of the "loop", see Figure 4.

Since the turbines would not operate correctly with less than 40 psig of pressure head, the following measures were taken:

1. The pressure gage at the turbine building was checked to ensure the correct pressure readings were observed. The gage was correct but was an easy check. 


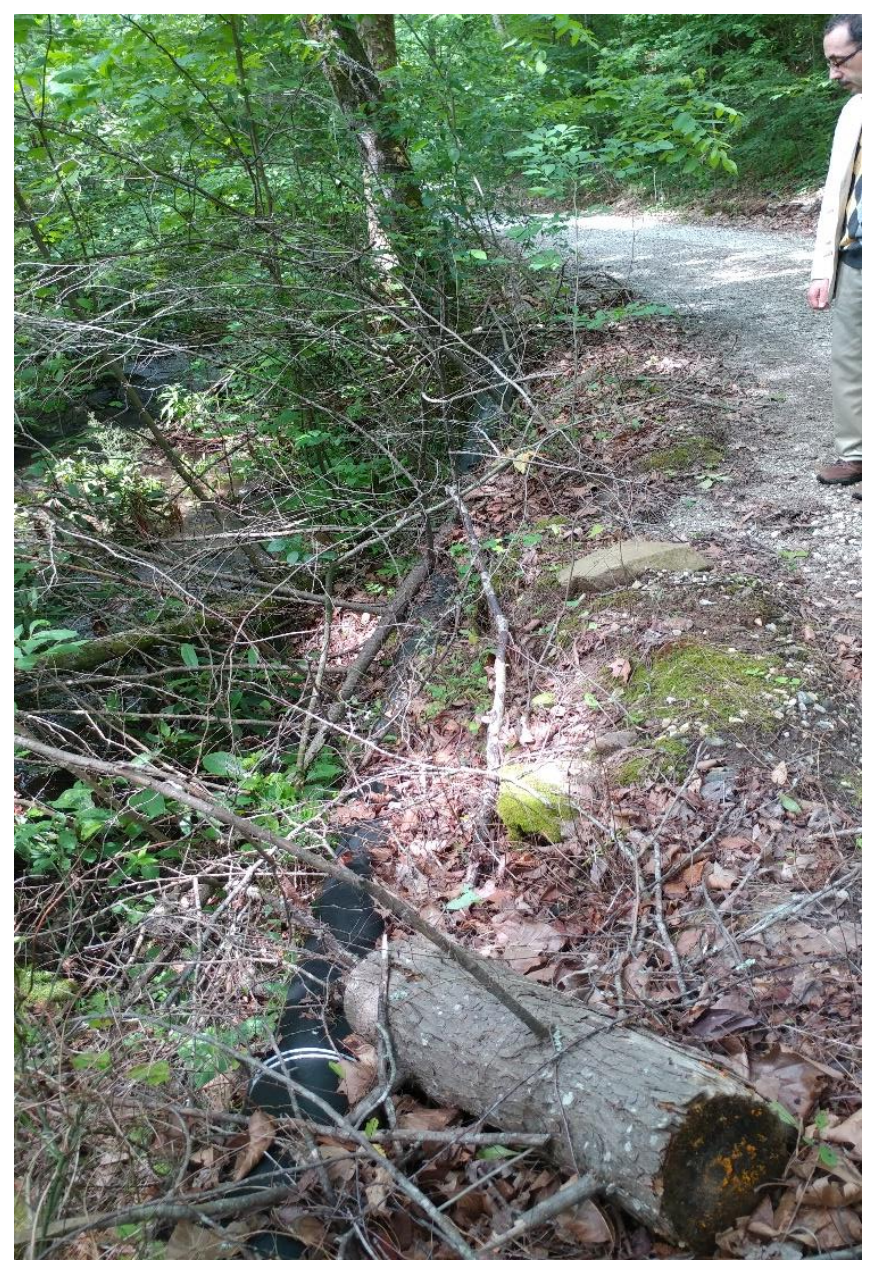

Figure 4

2. The suction line at the turbines was inspected to ensure that there were no obstructions to flooding the turbine inlets.

3. The pipeline was reset to ensure uniform elevation drop in the pipeline to allow air to be vented. One would expect air to rise into the highest point in a pipe, but the sagging loops were trapping water.

These measures addressed the static pressure issue. Once a sufficient static pressure of $42 \mathrm{psig}$ was achieved, the residual, water flowing, operating pressure was checked to ensure that the pipeline was not fouled or blocked by debris. Observations of pipeline pressure were made during some trial runs of the turbines, and no significant pressure issues were noted, indicating no significant blockages. The turbines operated correctly after fixing the sagging pipeline sections. 


\section{Conclusion}

This project involved students and faculty from three College of Engineering departments under the supervision of the Rapid Center. An Electrical Engineering faculty and a licensed mechanical engineer in the Construction Management faculty were involved in checking the turbine capabilities and pipeline design, respectively. Graduate students in the Master of Science in Technology program provided the muscle needed to complete the project and learned how an interdisciplinary team interacts to solve potential technical issues in the real world in real time. The two faculty members of the team explained each facet of the problem solving, remedy installation process to the graduate students during the site visits. A process to match faculty members' expertise was also modeled for future collaborative Rapid Center projects.

The community involvement with the fish farm company that owns the turbines and the AEOM was positive, supporting future collaborations, and the University's outreach mission per TAC of ABET's Criterion 2, and the Criterion 3 student learning outcomes:

“(d) an ability to design systems, components, or processes for broadly-defined engineering technology problems appropriate to program educational objectives;

(e) an ability to function effectively as a member or leader on a technical team;

(f) an ability to identify, analyze, and solve broadly-defined engineering technology problems." [4]

The lessons learned would be informally disseminated to students in the College's undergraduate programs indirectly in the engineering and engineering technology classrooms.

\section{References}

[1] Rapid Center website. (2017). Available at https://www.wcu.edu/learn/departments-schoolscolleges/cet/rapid-center/about-the-rapid-center.aspx .

[2] Energy Systems and Design Ltd. (2015). Stream Engine Owner's Manual. PO Box 4557 Sussex NB Canada E4E 5L7. Pg5

[3] Crane Co. (1988). Flow of Fluids, Technical Paper 410. 800 Third Ave, King of Prussia, PA 19406

[4] Accreditation Board for Engineering and Technology, Inc website. (2018). Criteria for Accrediting Engineering Technology Programs, 2018 - 2019. Available at: 
http://www.abet.org/accreditation/accreditation-criteria/criteria-for-accreditingengineering-technology-programs-2018-2019/\#program . 